GENE 06068

\title{
Chimerization of antibodies by isolation of rearranged genomic variable regions by the polymerase chain reaction
}

(Hybridoma; transfectoma; force cloning; cassette vectors; PCR; recombinant DNA)

\author{
Winfried Weissenhorn ${ }^{a}$, Elisabeth Weiss ${ }^{a}$, Marina Schwirzke ${ }^{b}$, Brigitte Kaluza ${ }^{b}$ and Ulrich H. Weidle ${ }^{b}$ \\ "Institut für Immunologie der Universität München, D-8000 Munich (F.R.G.) Tel. (49-89)5996-689; and "Boehringer Mannheim GmbH, \\ Abteilung für DNS-Neukombination, D-8122 Penzberg (F.R.G.)
}

Received by H.G. Zachau: 14 January 1991

Revised/Accepted: 14 April/10 July 1991

Received at publishers: 30 July 1991

\section{SUMMARY}

We describe a new method for amplification, by polymerase chain reaction (PCR), of rearranged segments encoding the variable part of light and heavy chains of an antibody $(\mathrm{Ab})$ from the chromosomal DNA of hybridoma cells for the chimerization of Abs. A fundamental prerequisite for this is the knowledge of the exact sequences in the 5 '-untranslated region of light and heavy chain mRNA, and of the joining segment used for rearrangement. This allows the design of nondegenerated oligodeoxyribonucleotides for PCR. The primer design permits directional cloning of the amplified, promoterless fragments into cassette vectors, in which they will be linked to the appropriate human constant domains and immunoglobulin (Ig) promoter/enhancer elements. The method is illustrated for chimerization of an Ab directed against the human T-lymphocyte antigen, $\mathrm{CD} 4$. The chimerized $\mathrm{Ab}$ is secreted in abundant quantities after transfection of the engineered plasmids into non-Ig-producing myeloma cells.

\section{INTRODUCTION}

The benefits of mAbs in the treatment of human diseases, such as autoimmune diseases, graft rejections and cancer

Correspondence to: Dr. U.H. Weidle, Boehringer Mannheim GmbH, Abteilung für DNS-Neukombination, Nonnenwald 2, Postfach 1152, D-8122 Penzberg (F.R.G.)

Tel. (49-8856)60-2801; Fax (49-8856)8744.

Abbreviations: aa, amino acid(s); Ab, antibody; Ap, ampicillin; bp, base pair(s); C, constant region; cDNA, DNA complementary to mRNA; D, diversity region; ELISA, enzyme-linked immunosorbent assay; Fab fragments, antigen-binding fragments of Abs that are derived by papain digestion and contain the light chain and part of the heavy chain (variable region and first constant domain); $\mathrm{H}$, heavy chain of $\mathrm{Ab}$; Ig, immunoglobulin; $\mathbf{J}$, joining region; kb, kilobase(s) or $1000 \mathrm{bp}$; $\mathrm{L}$, light chain of $\mathrm{Ab}$; $\mathrm{mAb}$, monoclonal $\mathrm{Ab}$; $\mathrm{nt}$, nucleotide(s); oligo, oligodeoxyribonucleotide; $\mathrm{PA}$, polyacrylamide; PCR, polymerase chain reaction; ss, single strand(ed); $U T$, untranslated region; $\mathrm{V}_{\mathrm{H}}$, variable heavy chain; $\mathrm{V}_{1}$, variable light chain. are now widely accepted. A major progress toward therapeutic applicability was the construction of chimeric Abs with variable rodent and constant human domains (Verhoeyen and Riechmann, 1988). Substantially lower immunogenicity has been found for chimeric Abs compared to their murine counterparts in colon cancer patients (Lo Buglio et al., 1989). With the advent of PCR technology (Saiki et al., 1985; 1988) cloning of cDNAs for $\mathrm{L}$ and $\mathrm{H}$ chains of Ig genes has been dramatically facilitated by making use of degenerate oligos (LeBœuf et al., 1989; Orlandi et al., 1989; Huse et al., 1989; Larrick et al., 1989). For expression, the $V_{\mathrm{L}}$ and $V_{\mathrm{II}}$ regions have to be cloned into vectors carrying the appropriate constant human region thus mimicking $I g$ genes. In contrast to Ig cDNAs, Ig genes are well expressed in Ig nonproducer hybridoma cells (Weidle et al., 1987). For this purpose, the isolated $V$ regions have to be mutagenized to match the reading frame of the $I g$ gene on the vector. Alternately, restriction sites have to be incorporated into the primers for directed cloning 
and expression (Orlandi et al., 1989). In this paper we present a different approach for cloning the relevant $V_{\mathrm{L}} J$ and $V_{H} D J$ regions with non-degenerate primers. Our technique includes PCR amplification of specific genomic DNA fragments and their subsequent force-cloning into cassette vectors. To our knowledge, this is the first report on the cloning of rearranged $V_{\mathrm{L}} J$ and $V_{\mathrm{H}} D J$ regions from genomic DNA by PCR. In contrast to the procedure described by Orlandi et al. (1989), the expressed $A b$ gene retains its authentic signal peptide sequence (including introns) and does not differ at the $\mathrm{N}$-terminal aa from the original murine $\mathrm{Ab}$.

\section{EXPERIMENTAL AND DISCUSSION}

\section{(a) Principle of the method for chimerization}

The most important prerequisite for the new method of chimerization is the knowledge of the exact sequence of the 5'UT region of the mRNA and of the $J$ region used for the $V_{\mathrm{L}} J$ and $V_{\mathrm{H}} D J$ rearrangement for the $\mathrm{L}$ and $\mathrm{H}$ chain of the $\mathrm{Ab}$. This information allows the design of nondegenerate primers for the isolation of the relevant $V_{\mathrm{l}} J$ and $V_{\mathrm{H}} D J$
Primer a: 5'-GATCGTCGACAAGACTCAGCCTGGACATGATGTCC

$\overline{S a l l} \ldots \ldots \ldots \ldots \ldots \ldots \ldots$

Primer b: 5 -ATCAGCGGCCGCACTTAACAAGGTTAGACTTAGTG

Notl $\cdots \cdots \cdots \cdots \cdots \cdots$

Primer c: 5'-CATAGTCGACGTTAGTCTTAAGGCACCACTGAGCC

Sall $\cdots \cdots \cdots \cdots \cdots \cdots \cdots \cdots$

Primer d: $5^{\prime}$-GAGCGCGGCCGCTTAAAAATAAAGACCTGGAGAGGCCA

Notl $\quad \cdots \cdots \cdots \cdots \cdots \cdots$

Fig. 1. Primers used for amplification of $V_{1} J$ and $V_{11} D J$ regions of $\mathrm{mAb}$ MT15I by PCR. Primers $a$ and $b$ were used for amplification of the $V_{3} J$ region, $\mathbf{c}$ and $\mathbf{d}$ for the amplification of the $V_{11} D J$ region of $\mathrm{mAb} M T 151$. Primers $\mathbf{a}, \mathbf{b}$ and $\mathbf{c}$ are 35 -mers, and primer $\mathbf{d}$ is a 38 -mer. The numbers of matching nt for primers $\mathbf{a}, \mathbf{b}, \mathbf{c}$ and $\mathbf{d}$ are 25,23, 25 and 26. Primers were synthesized on an Applied Biosystems (Foster City, CA) oligo synthesizer. The $5^{\prime}$ primers contain in their overhanging part four ut and a $S a l l$ recognition site, the matching part corresponds to nt in the $5^{\prime} U T$ region of $x$ and the $12 \mathrm{~m}$ mNA. The 3 ' primers contain in their nonmatching part four random nt and a $N o t I$ recognition site, in their matching part $23 \mathrm{nt}$ corresponding to the $J_{2}$ intron of the L-chain encoding gene and to the $J_{4}$ intron of the H-chain encoding gene. Restriction sites are underlined. Dashed lines represent Ig gene sequences.

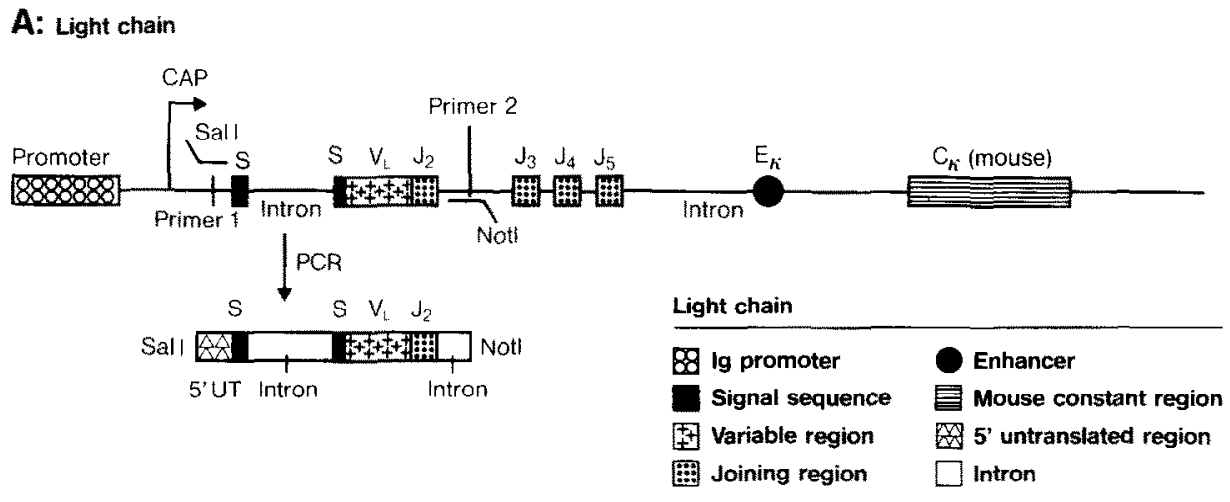

B: Heavy chain

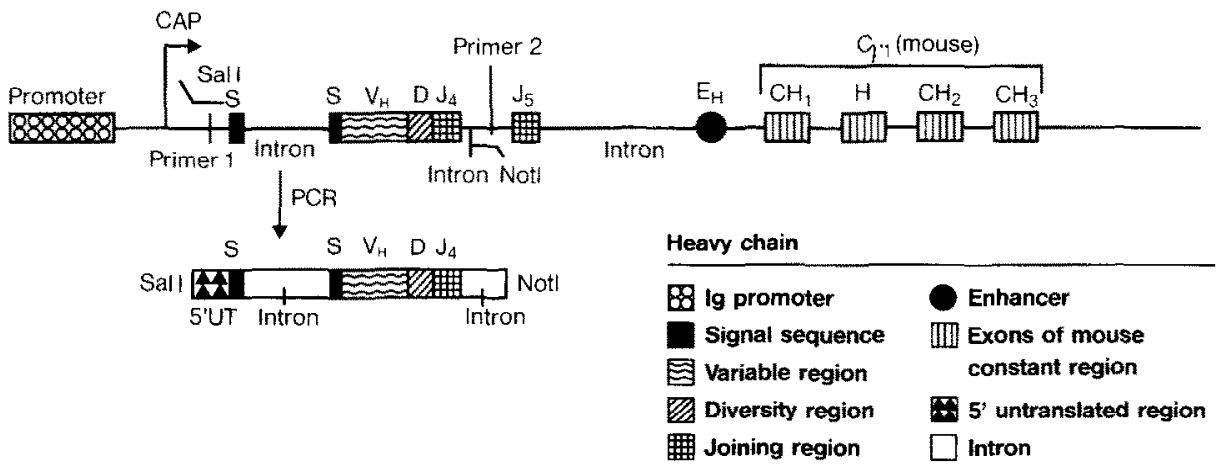

Fig. 2. Schematic representation of the chimerization method. The procedure is shown for the $L$ chain $(\mathbf{A})$ and for the $H$ chain (B). PCR amplification with primers complementary to the $5^{\prime} \mathrm{UT}$ region of the mRNA and to intron sequences $3^{\prime}$ to the $J$ segment used for rearrangement leads to $V_{\mathrm{t}} J$ and $V_{n} D I$ fragments with a $S a l l$ site at their $5^{\prime}$ ends and a $\mathrm{Not} I$ site at their $3^{\prime}$ ends for directed cloning into cassette vectors with $I g$ promoter elements and the appropriate human constant regions. A general outline of the procedure is described in section a. $C$, constant region; $C A P$, initiation site for $\mathrm{mRNA}, D$, diversity region; $E_{h}$ and $E_{1\}}$, enhancers for light and heavy chain; $H$, hinge region; $J$, joining region; $S$, signal sequence; $V_{1}$, and $V_{11}$, variable region of $L$ and $H$ Ig genes. 
regions from DNA of the hybridoma cell line by PCR. The primers (Fig. 1) are designed as follows: (a) and (c) 5' primers matching to the $5^{\prime} \mathrm{UT}$ regions of $\mathrm{L}$ and $\mathrm{H}$ chain mRNA. They include at their $5^{\prime}$ end a restriction enzyme cleavage site ( $S$ all $)$ useful for force cloning. Primers (b) and (d) are the $3^{\prime}$ primers matching the intron sequences downstream from the $J$ region used for the rearrangement. This is possible because the $J$ loci for the $\mathrm{L}$ and $\mathrm{H}$ chains of the mouse are completely sequenced (Max, 1981; Sakano et al., 1980). The $3^{\prime}$ primers include a Not I cleavage site at their $5^{\prime}$ ends for force cloning of the amplified fragments. As a result of the amplification procedure promoterless $V_{\mathrm{L}} J$ and $V_{\mathrm{H}} D J$ fragments are obtained including its intron, the $V_{\mathrm{L}} J$ or $V_{\mathrm{H}} D J$ region and intron sequences $3^{\prime}$ from the $J$ region used for rearrangement including the splice donor consensus GT (Fig. 2). The resulting amplified $V_{\mathrm{L}} J$ and $V_{\mathrm{H}} D J$ fragments are endowed with a SalI site at their $5^{\prime}$ ends and a NotI site at their $3^{\prime}$ ends for directed cloning into a cassette vector containing Ig promoter elements and appropriate human constant regions.

\section{(b) Application of the technique to the chimerization of an anti-CD4 antibody}

The mAb MT151 ( $\left.\operatorname{IgG}_{2 \mathrm{a}}\right)$ binds to an epitope in the first extracellular loop of the human T lymphocyte surface antigen CD4 (Reinherz et al., 1986). The murine Ab has been successfully used in the treatment of patients with rheumatoid arthritis (Herzog et al., 1987). Therefore, a chimerized, less immunogenic version of this $\mathrm{Ab}$ is of great im-

portance for clinical applications. The sequence of the $5^{\prime} U T$ and the $\mathrm{V}$ regions of the $\kappa$ and $\gamma_{2 \mathrm{a}}$ chains of mAb MT151 was determined as described in the legend to Fig. 3. We identified rearrangement of $V_{\mathrm{T}}$, with the $J$, segment of the $\mathrm{L}$ chains and of $V_{\mathrm{H}}$ with $J_{4}$ of the $\mathrm{H}$ chains. This information enabled us to synthesize $5^{\prime}$ and $3^{\prime}$ primers for amplification of the rearranged $V J$ and $V D J$ segment by PCR (Fig. 1). For the light chain, a 600-bp $V_{\mathrm{L}} J$ fragment, and for the heavy chain, an approx. 700-bp $V D J$ fragment was amplified (Fig. 3). The fragments with $S a l I$ and $N o t I$ sites were subcloned and the sequences of five isolates for each chain were determined (Sanger et al., 1977). Compared to the cDNA sequence we detected an exchange in one of the five $V_{\mathrm{L}} J$ isolates as well as in one of the five $V_{\mathrm{H}} D J$ isolates duc to the high error rate of Taq polymerase. We have applied the described technique to isolate the $V_{\mathrm{L}} J$ and $V_{\mathrm{H}} D J$ segments of the two additional mAbs, one directed against an epitope on human CD4 different from that of mAb MT151 and another binding to the $\alpha$-chain of the human interleukin-2 receptor. Also for these two mAbs fragments in the range of 600-700 bp were amplified (data not shown). Sequencing of five isolates of subcloned $V_{\mathrm{L}} J$ and $V_{\mathrm{H}} D J$ regions for each $\mathrm{Ab}$ revealed that the error rate of $T a q$ polymerase was comparable to that obtained for $\mathrm{mAb}$

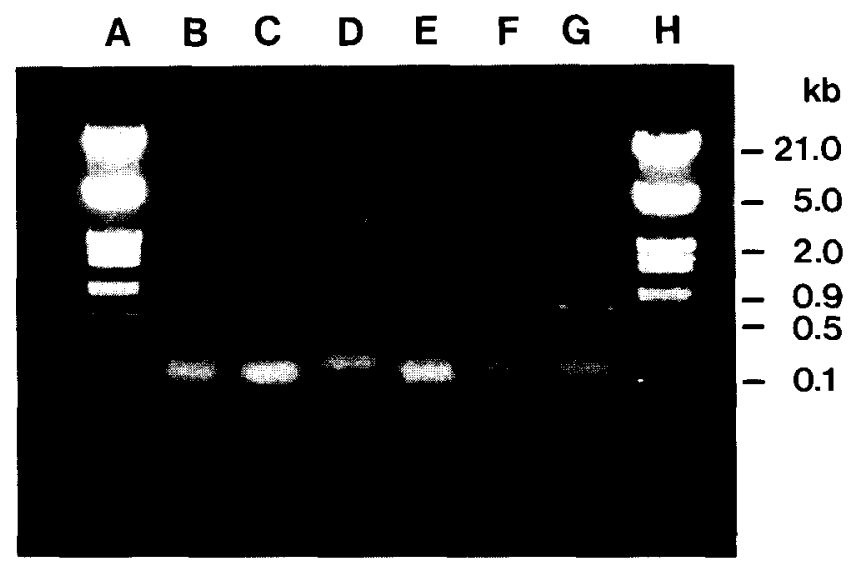

Fig. 3. Amplification of $V_{\mathrm{L}} J$ and $V_{\mathrm{H}} D J$ regions encoding $\mathrm{mAb}$ MT151 by PCR. Lanes: $\mathbf{A}$ and $\mathbf{H}$, marker fragments; $\mathbf{B}$ and $\mathbf{F}$, control PCR (minus DNA); C, amplification with primers $\mathbf{c}$ and $\mathbf{d} ; \mathbf{D}$ and $\mathbf{E}$, amplification with $\gamma$ primers different from those shown in Fig. 1; G, amplification with $\kappa$ primers $\mathbf{a}$ and $\mathbf{b}$. The sequences of primers $\mathbf{a}, \mathbf{b}, \mathbf{c}$ and $\mathbf{d}$ are shown in Fig. 1. Methods. For cDNA cloning and sequence determination RNA was isolated from $2 \times 10^{7}$ cells (Chirgwin et al., 1979). The RNA pellet $\left(250 \mu \mathrm{g}\right.$ ) was dissolved in $12.5 \mu \mathrm{l} \mathrm{H}_{2} \mathrm{O}$, incubated with $375 \mu \mathrm{l}$ dimethylsulfoxide for $20 \mathrm{~min}$ at $45^{\circ} \mathrm{C}$, ethanol-precipitated and dissolved in $\mathrm{H}_{2} \mathrm{O}$. Synthesis of cDNA was performed with $200 \mu \mathrm{g}$ RNA and $20 \mathrm{ng}{ }^{32} \mathrm{P}$. labelled primers with the first-strand buffer of the BRL cDNA synthesis kit according to the instructions of the manufacturer. $\kappa$ primer: $5^{\prime}-\mathrm{GAA}$ GATGGATACAGTTGGIGC $\gamma$ primer: S'GGCCAGTGGAIAGACAGATGG. These primers match the 5 ' part of the constant regions of the $k$ and the $\gamma$ chain. After treatment of the ss DNA with $50 \mu \mathrm{g}$ RNase A for $30 \mathrm{~min}$, phenolization and ethanol precipitation, the ssDNAs were size-fractionated on a $5 \% \mathrm{PA}$ gel and the position of the $V_{\mathrm{L}}$ and $V_{\mathrm{H}}$ fragments visualized by autoradiography. The bands were excised, DNA eluted with $2 \mathrm{M} \mathrm{NH}_{4}$. acetate at $37^{\circ} \mathrm{C}$, precipitated, and tailed with $\mathrm{G}$ residues with terminal deoxynucleotidyl-transferase (Maniatis et al., 1982). After phenol extraction and ethanol precipitation, the ss DNA was dissolved in $10 \mu \mathrm{l} \mathrm{H}_{2} \mathrm{O} .3 \mu \mathrm{l}$ were used for the following PCR reaction. $10 \mathrm{pmol}$ of $5^{\prime}$ and $3^{\prime}$ oligos were used in a $20 \mu \mathrm{l}$ reaction in $10 \mathrm{mM}$ Tris $\cdot \mathrm{HCl} \mathrm{pH} 8.4 / 50 \mathrm{mM} \mathrm{KCl} / 1 \mathrm{mM} \mathrm{MgCl} / 0.1 \mathrm{mM} \mathrm{dNTPs}$ and $T a q$ polymerase. 5' primer: 5'-GCATGCGCGCGGGCCGCGGAGGCCCCCCCCCCCCCC (contains sites for SacII, SphI, NotI and SfiI; Loh et al., 1989). The $3^{\prime}$ primer contains an EcoRI cleavage site near the $5^{\prime}$ end and matches the nt of the $5^{\prime}$ part of the constant regions of $\kappa$ and $\gamma$ mRNA. 3' primer $\kappa$ : 5'-GGGAATTCTGGTGCAGCATCAGCCC. 3' primer $\gamma$ '5'-GGGAATTCGATAGACAGATGGGGGTG. The reaction was carried out in a Perkin-Elmer cycler with the following conditions: $5 \mathrm{~min}$ at $94^{\circ} \mathrm{C}, 2 \mathrm{~min}$ at $42^{\circ} \mathrm{C}$, five cycles ( 1 min each) at $72^{\circ} \mathrm{C}, 1 \mathrm{~min}$ at $94^{\circ} \mathrm{C}, 1 \mathrm{~min}$ at $55^{\circ} \mathrm{C}, 20$ cycles at $72^{\circ} \mathrm{C}(1 \mathrm{~min}$ each $)$, $10 \mathrm{~min}$ at $72^{\circ} \mathrm{C}$. An aliquot of the PCR products was size-fractionated on a $1 \%$ low-melting-agarose gel, the amplified DNA was eluted, cleaved with $E c o R I+N o t I$, subcloned and the sequence determined by the dideoxy method (Sanger et al., 1977). Reaction conditions for PCR amplification with primers a, b, $\mathbf{c}$ and d: $10 \mathrm{mM}$ Tris $\cdot \mathrm{HCl} \mathrm{pH} 8.3 / 50 \mathrm{mM}$ $\mathrm{KCl} / 1.5 \mathrm{mM} \mathrm{MgCl} / 2.1 \%(\mathrm{w} / \mathrm{v})$ gelatine $/ 1 \mu \mathrm{g}$ chromosomal DNA $/ 5^{\prime}$ and 3' primer $1 \mu \mathrm{g}$ each/dATP, dGTP, dCTP, dTTP $200 \mu \mathrm{M}$ each/Taq polymerase (Boehringer-Mannheim) 2.5 units in a reaction volume of $100 \mu \mathrm{l}$. The reaction mixture was overlayered with $100 \mu 1$ mineral oil (Sigma). The reaction mixture was kept at $92^{\circ} \mathrm{C}$ for $5 \mathrm{~min}$, then for $2 \mathrm{~min}$ at $55^{\circ} \mathrm{C}$ and $2 \mathrm{~min}$ at $72^{\circ} \mathrm{C}$. Before the following 26 cycles at $72^{\circ} \mathrm{C}$ ( 2 min each) the mixture was kept for $2 \mathrm{~min}$ at the temperatures indicated above. $10 \%$ of the mix was size-fractionated on a $1.5 \%$ low-melting-point agarose gel $(0.5 \mu \mathrm{g}$ ethidium bromide $/ \mathrm{ml})$, the amplified DNA was isolated, cleaved with $S a l I+N o t I$ and ethanol-precipitated. 


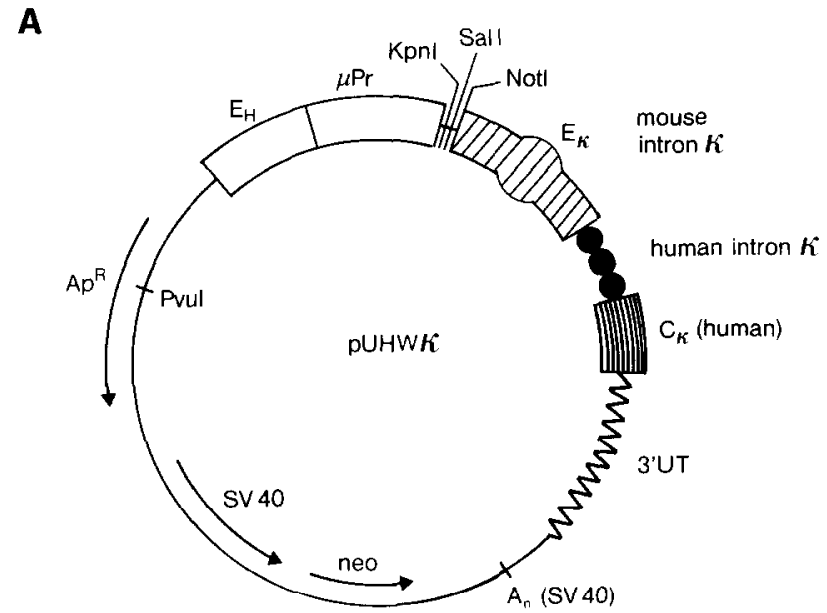

B

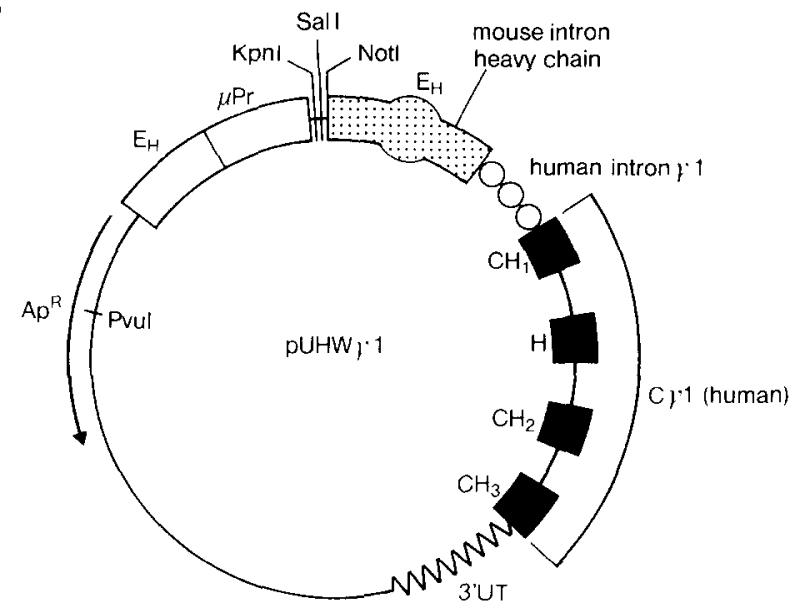

Fig. 4. Expression vectors for chimeric $\mathrm{Ab}$ in non-Ig producer hybridoma cells. Amplified $V_{\mathrm{L}} J$ and $V_{\mathrm{H}} D J$ fragments encoding mAb MT151 (Fig. 3) were cloned as SalI-NotI fragments into cassette vectors pUHW $k$ (A), and pUHW $\gamma 1$ (B) (which were cleaved with $S a l I+N o t I$ ) to give rise to vectors pUHW-CD $4 \kappa$ and pUHW-CD $4 \gamma 1$ by forced cloning. As promoter elements both vectors contain a combination of a heavy-chain enhancer $\left(E_{H}\right)$, and a $\mu$ gene promoter $(\mu \operatorname{Pr})$ (Weidle et al., 1987). Both vectors contain a polylinker including unique $K p n I$, SalI and $N_{o t} \mathrm{I}$ sites. Plasmid pUHW $\kappa$ contains the constant region of a human $\kappa$ gene and is based on pSV2neo (Southern and Berg, 1982). The plasmid contains a hybrid light-chain intron with mouse and human elements. Plasmid pUHW $K$ contains the mouse light-chain enhancer region as a $2-\mathrm{kb}$ Eco RI-Asp 700 fragment (Picard and Schaffner, 1984) and a part of the human light chain intron, the human $\kappa$ exon and $3^{\prime} U T$ region as a $2.8-\mathrm{kb}$ fragment from pCl (Klobeck et al, 1984). Plasmid pUHW $\gamma 1$ is the cassette vector for the insertion of amplified $V_{\mathrm{H}} D J$ fragments. It contains the mouse heavy-chain enhancer region as a 1.6-kb HindIII-Eco RI fragment (Neuberger, 1983) and part of the human heavy-chain intron, the four exons and three introns and $3^{\prime} U T$ region of the human $\gamma 1$ gene as a 7-kb HindIII fragment (Takahashi et al., 1984). Plasmids pUHW$\mathrm{CD} 4 \kappa$ and $\mathrm{pUHW}-\mathrm{CD} 4 \gamma 1$ were linearized at their unique $P v u \mathrm{I}$ sites and an equimolar mixture of both plasmids ( $5 \mu \mathrm{g}$ per $10^{6}$ cells) was transfected into $\mathrm{Sp} 2 / 0$ cells (Ochi et al., 1983) by electroporation. Stable transfectants were isolated by selection with $\mathrm{G} 418(1000 \mu \mathrm{g} / \mathrm{ml})$ as descrihed (Lenz and Weidle, 1990) and reconstituted $\mathrm{Ab}$ was quantified by ELISA. $\mu \mathrm{Pr}$, promoter of a mouse $\mu$ gene; $\mathrm{E}_{\kappa}$ and $\mathrm{E}_{\mathbf{H}}$, enhancers of light and heavy chains of the mouse, respectively: $3^{\prime} U T, 3^{\prime}$ untranslated region;
MT151. The size of the intron which separates the signal sequences was in the range between 60 and $120 \mathrm{nt}$, when the six isolates of the three mAbs were compared (data not shown). All three mAbs make use of different $J$ segments. From these observations we conclude that the method is of general applicability. After sequencing, the amplified SalINot I fragments $\left(V_{\mathrm{L}} J\right.$ and $\left.V_{\mathrm{H}} D J\right)$ of mAb MT151 were force-cloned into cassette vectors pUHW $\kappa$ (with a human $\kappa$ constant region) and $\mathrm{pUHW} \gamma 1$ (with a human $\gamma 1$ constant region). The vectors are displayed in Fig. 4. Both vectors make use of heavy-chain enhancer and promoter elements at the $5^{\prime}$ end of the $V_{\mathrm{l}} J$ and $V_{\mathrm{H}} D J$ fragments to be inserted by force-cloning and can be linearized at their unique $P v u l$ sites in the $\mathrm{Ap}^{R}$ gene before transfection into hybridoma cells. Plasmids pUHW $\kappa \mathrm{CD} 4$ and pUHW $\gamma$ CD4 obtained after ligation of the appropriate $V_{\mathrm{L}} J$ and $V_{\mathrm{H}} D J$ fragments into $p U H W \kappa$ and $p U H W \gamma 1$ were transfected into $\mathrm{Sp} 2 / 0$ cells (Ochi et al., 1983) and stable transformants were isolated by G418 selection. Transformants expressing up to $10 \mu \mathrm{g} / \mathrm{ml}$ of chimerized $\mathrm{Ab}$ per $10^{6}$ cells and $24 \mathrm{~h}$ were obtained.

\section{(c) Conclusions}

(l) We demonstrated for the first time the feasibility of cloning rearranged genomic $V_{\mathrm{L}} J$ and $V_{\mathrm{H}} D J$ segments of $\mathrm{Ab}$ with PCR and nondegenerate oligos.

(2) After the PCR, the amplified promoterless fragments can be directionally cloned into cassette vectors carrying the appropriate human constant regions.

(3) The method seems to be of general applicability because it has been applied successfully to the chimerization of $\mathrm{Ab}$ from three different hybridoma cell lines.

(4) Contrary to previous approaches making use of cDNA cloning, mutation and insertion into expression vectors, authentic $V_{\mathrm{L}} J$ and $V_{\mathrm{H}} D J$ genomic segments are isolated by our method.

(5) High-level synthesis of chimerized $\mathrm{Ab}$ was monitored after transfection of expression vectors with human $\kappa$ and $\gamma l$ constant regions and the $V_{\mathrm{L}} J$ and $V_{\mathrm{H}} D J$ regions of the murine $\mathrm{Ab}$ into non-Ig-producer myeloma cells.

\section{ACKNOWLEDGEMENTS}

Our work was partly supported by BMFT (Bundesministerium für Forschung und Technologie) and Genzentrum München. Thanks are due to Dr. Sandro Rusconi for reading this paper instead of a dull magazine in the train and Brigitte Kindermann for help with the preparation of the

$A_{n}(S V 40)$, polyadenylation signal derived from simian virus $40 ; H$, exon coding for hinge region; $\mathrm{Ch}_{1}, \mathrm{CH}_{2}, \mathrm{CH}_{3}$, exons of the human $\gamma 1$ gene. Arrows indicate the direction of transcription. 
manuscript. We are indebted to Drs. T. Honjo and H.G. Zachau for providing us with plasmids.

\section{REFERENCES}

Chirgwin, J.M., Przybyla, A.E., MacDonald, R.J. and Rutter, W.J.: Isolation of biologically active ribonucleic acid from sources enriched in ribonuclease. Biochemistry 18 (1979) 5294-5299.

Herzog, C., Walker, C., Pichler, W., Aeschlimann, A., Wassmer, P., Stockinger, H., Knapp, W., Rieber, E.P. and Müller, W.: Monoclonal anti-CD4 in arthritis. Lancet 2 (1987) 1461-1462.

Huse, W.D., Lekshmi, L., Iverson, S., Kang, A.S., Alting-Mees, M., Burton, D.R., Benkovic, S.J. and Lerner, R.: Generation of a large combinatorial library of the immunoglobulin repertoire in phage lambda. Science 246 (1989) 1275-1281.

Klobeck, H.-G., Combriato, G. and Zachau, H.G.: Immunoglobulin genes of the light chain type from two human lymphoid cell lines are closely related. Nucleic Acids Res. 12 (1984) 6995-7006.

Larrick, J.W., Daniellson, L., Brenner, C.A., Wallace, E.F., Abrahamson, M., Fry, K.E. and Borrebaeck, C.A.K.: Polymerase chain reaction using mixed primers: cloning of human monocional antibody variable region genes from single hybridoma cells. Bio/Technology 7 (1989) 934-938.

LeBouf, R.D., Galin, F.S., Hollinger, S.K., Peiper, S.C. and Blalock, J.E.: Cloning and sequencing of immunoglobulin variable-region genes using degenerate oligodeoxyribonucleotides and polymerase chain reaction. Gene 82 (1989) 371-377.

Lenz, H. and Weidle, U.H.: Expression of heterobispecific antibodies by genes transfected into producer hybridoma cells. Gene 87 (1990) 213-218.

Lo Buglio, A.F., Wheeler, R.H., Trang, J., Haynes, A., Rogers, K., Harvey, E.B., Sun, L., Ghrayeb, J. and Khazeli, M.B.: Mouse/human chimeric monoclonal antibody in man: kinetics and immune response: Proc. Natl. Acad. Sci. USA 86 (1989) 4220-4224.

Loh, E.Y., Elliott, J.F., Cwirla, S., Lanier, L.L. and Davies, M.M.: Polymerase chain reaction with single sided specificity: analysis of $\mathrm{T}$ cell receptor delta chain. Science 243 (1989) 217-220.

Maniatis, T., Fritsch, E.F. and Sambrook, J.: Molecular Cloning. A Laboratory Manual. Cold Spring Harbor Laboratory, Cold Spring Harbor, NY, 1982.

Max, E.E.: The nucleotide sequence of a 5.5-kilobase DNA segment containing the mouse kappa immunoglobulin $\mathrm{J}$ and $\mathrm{C}$ region genes. J. Biol. Chem. 256 (1981) 5116-5120.
Neuberger, M.: Expression and regulation of immunoglobulin heavy chain gene transfected into lymphoid cells. EMBO J. 2 (1983) 1373-1378.

Ochi, A., Hawley, R.G., Hawley, T., Shulman, M.J., Traunecker, A., Köhler, G. and Hozumi, N.: Functional immunoglobulin M production after transfection of cloned immunoglobulin heavy chains into lymphoid cells. Proc. Natl. Acad. Sci. USA 80 (1983) 6351-6355.

Orlandi, R., Güssow, D.H., Jones, P.T. and Winter, G.: Cloning immunoglobulin variable domains for expression by the polymerase chain reaction. Proc. Natl. Acad. Sci. USA 86 (1989) 3833-3837.

Picard, D. and Schaffner, W.: A lymphocyte-specific enhancer in the mouse immunoglobulin gene. Nature 307 (1984) 80-82.

Reinherz, E.L., Nadler, L.M., Haynes, B.F. and Bernstein, I.D.: Leukocyte Typing II, Vol. 1: Human T Lymphocytes. SpringerVerlag, New York, 1986.

Saiki, R.K., Scharf, S., Faloona, F., Mullis, K.B., Horn, G.T., Erlich, H.H. and Arnheim, N.: Enzymatic amplification of $\beta$-globin genomic sequences and restriction site analysis for diagnosis of sickle-cell ancmia. Sciencc 230 (1985) 1350-1354.

Saiki, R.K., Gelfand, D.H., Stoffel, S., Scharf, S.J., Higuchi, R., Horn, G.T., Mullis, K.B. and Erlich, H.A.: Primer-directed enzymatic amplification of DNA with a thermostable DNA polymerase. Science 239 (1988) 487-491.

Sakano, H., Maki, R., Kurosawa, Y., Roeder, W. and Tonegawa, S.: Two types of somatic recombination are necessary for the generation of complete immunoglobulin heavy-chain genes. Nature 286 (1980) $676-683$.

Sanger, F., Nicklen, S. and Coulson, A.R.: DNA sequencing with chainterminating inhibitors. Proc. Natl. Acad. Sci. USA 74 (1977) 5463-6467.

Southern, P. and Berg, P.: Transformation of mammalian cells to antibiotic resistance with a bacterial gene under the control of the SV40 early region promoter. J. Mol. Appl. Genet. 1 (1982) 327-341.

Takahashi, N., Noma, T. and Honjo, T.: Rearranged immunoglobulin heavy chain variable region $\left(\mathrm{V}_{\mathrm{H}}\right)$ pseudogene that deletes the second complementarity determining region. Proc. Natl. Acad. Sci. USA 81 (1984) 5194-5198.

Verhoeyen, M. and Riechmann, L.: Engineering of antibodies. BioEssays 8 (1988) 74-78.

Weidie, U.H., Koch, S. and Buckel, P.: Expression of antibody cDNA in murine myeloma cells: possible involvement of additional regulatory elements in transcription of immunoglobulin genes. Gene 60 (1987) 205-216. 